\title{
Phonological Awareness among Kannada Speaking Children: Analysis of Performance on Different Components of Phonological Awareness
}

\author{
Karibasappa C. Nagaraja ${ }^{1}$, Sampathkumar ${ }^{2}$
}

\section{ABSTRACT}

This study explores the performance on different components of the phonological awareness (i.e., rhyme generation (RG), phoneme deletion (PD), phoneme reversal (PR), syllable deletion (SD), syllable reversal (SR) and spoonerism (Spo) among $4^{\text {th }}, 5^{\text {th }}$ and $6^{\text {th }}$ grade children. A total of 110 children $\left(31-4^{\text {th }}, 41-5^{\text {th }}\right.$ and $38-6^{\text {th }}$ graders) spoke only one language, and Kannada was their mother tongue. The results indicate that there is a slight increase in performance on all components of phonological awareness. However, there are no significant differences in performance on component skills of phonological awareness across the grades observed except from syllable reversal. The results also reveal that a better performance, from all the groups, on syllable and rime tasks when compared to phoneme level tasks.

Keywords: Phonological Awareness, Kannada Speaking Children, Performance

Reading is one of the most significant components of academic achievement both in early and later years. Acquiring good literacy skills is one of the important foundations for proper learning. Learning to speak does not need any deliberate training whereas acquisition of reading skills depend on the reading instructions provided. Learning how to read is one of the most important skills to master in early years of schooling.

Reading is an important literacy skill based on language. One's individual language ability contributes significantly in adequate development of reading (Gillon, 2000). Not all children have the same language abilityas; reading involves a network of skills, which depends on cognitive and linguistic factors to a large extent (Swank \& Catts, 1994). Achievement on reading will create a variance because of individual differences in cognitive and linguistic abilities.

\footnotetext{
${ }^{1} \mathrm{PhD}$ Research Scholar, DOS in Psychology, University of Mysore, Mysore, India

${ }^{2}$ Assistant Professor, DOS in Psychology, University of Mysore, Mysore, India

*Responding Author

(C) 2016, K Nagaraja, Sampathkumar; licensee IJIP. This is an Open Access Research distributed under the terms of the Creative Commons Attribution License (http://creativecommons.org/licenses/by/2.0), which permits unrestricted use, distribution, and reproduction in any Medium, provided the original work is properly cited.
} 


\section{Phonological Awareness among Kannada Speaking Children: Analysis of Performance on Different Components of Phonological Awareness}

In finding variables, which contribute in reading achievement, research studies reveal that there is a strong correlation between met linguistic skills and reading achievement. Out of these, Phonological awareness (PA) is among the one significant met linguistic abilities, which has a major contribution in reading development in children.

More than three decades of research has proved the close relationship between PA and reading acquisition. Furthermore good number of studies reveal that performance of children on various PA tasks is convincingly connected to the skills of reading acquisition in English (Bradley \& Bryant, 1985; Tunmer \& Nesdale, 1986), Italian (Cossu, Shankweiler, Liberman, Katz, \& Tola, 1988), French (Bertelson, Morais, Alegria, \& Content, 1985), Hebrew (Bentin \& Leshem, 1993) and Spanish (de Manrique \& Gramigna, 1984). Moreover, the longitudinal studies indicated a robust connection between PA and later reading achievement, suggesting a causal connection between reading performance and PA (Bradley \& Bryant, 1985; Muter, Hulme, Snowling, \& Taylor, 1997).

Conclusively, PA is an important factor contributing in reading development, and it is defined as the ability of awareness and access speech sound and manipulation of sound, segment and blend, at different levels (Wagner, Torgesen, Rashotte, Hecht, Barker, Burgess, et al., 1997, p. 469).

Major research works were done on English language, which indicate that PA plays an important role in reading acquisition of alphabetic languages (Calfee, Lindamood \& Lindamood 1973; Bradley \& Bryant 1983; Stanovich, Cunningham \& Cramer 1984; Tunmer \& Nesdale 1985; Juel, Griffith \& Gough 1986). As PA is a major predictive factor of reading acquisition, and across many European languages, children follow the same path in developing phonological awareness (Ziegler \& Goswami, 2005), however reading acquisition can vary, because of differences across languages in spelling to sound consistency, phonological representations and orthographic granularity, and method of teaching (Ziegler \& Goswami, 2005).

Reading performance is different across languages because it depends on facility or difficulty in learning to process phonemes and graphemes. If one letter maps on to only one phoneme or if one phoneme maps on to only one letter consistently it is relatively easier to master the phoneme when compared to one letter maps on to multiple sounds or one phoneme maps on to different letter or letter string. These differences in different languages may affect reading performance; we may expect that reading acquisition is more rapid in languages which have high graphemephoneme consistency (GPC) as opposed to languages which have low GPC (Ziegler \& Goswami, 2005).

Research studies, in different languages, show that phonological awareness is a significant factor however, the nature of the language influences phonological processing skills. As in English

(C) The International Journal of Indian Psychology, ISSN 2348-5396 (e)| ISSN: 2349-3429 (p) | 100 
language sub-syllabic skills are crucial in learning, many research studies show that phonological processing is crucial in predicting and promoting English language acquisition. Thus, reading difficulties, in English language learners, are caused by a deficit in phonological processing (Vellutino, Fletcher, Snowling\& Scanlon, 2004).

However, the consistency of the orthography influences the rate of phoneme awareness development and decoding skills, so the readers will gain competency more quickly in languages which have a consistent grapheme-phoneme relationship as opposed to English (Seymour, Aro \& Erskine, 2005). In the case of alphasyllabary, syllables incorporate phonemic information by distinguishable features at syllabic and sub-syllabic level (Bright, 1996). Research in alphasyllabaries; in Hindi (Vaid \& Gupta, 2002), Kannada (Nag, 2007), Korean (Cho \& Mc Bride-Chang, 2005; Simpson \& Kang, 2004), Telugu (Vasanta, 2004), and Thai (Winskel \& Iemwanthong, 2009), showed awareness of syllabic and sub-syllabic information is significant for reading words in alphasyllabary. Further research works prove that phonemic awareness can develop in alphasyllabary (Nag, 2007; Nag \& Snowling, 2011), however it does not develop until children reach $3^{\text {rd }}$ or $4^{\text {th }}$ grade (Nag, 2007; Cho \& McBridge-Chang, 2005).

The range of cognitive skills and script specific features involved in reading acquisition create an increased research interest in different languages to find the role of cognitive skills and linguistic features on reading development and reading failure. Research in different languages confirms that the role of phonological awareness is important in reading acquisition but it is not unanimously accepted as having a universal causal relationship of reading development and reading failure, across different languages. However, research studies started to explore the role of different component skills of phonological awareness in reading development and reading failure. In this direction, the present study reports findings of phonological awareness among children studying in $4^{\text {th }}, 5^{\text {th }}$ and $6^{\text {th }}$ grade Kannada medium school.

\section{Objective}

The objective of the present study is to explore the pattern of performance on different components of phonological awareness across tests of $4^{\text {th }}, 5^{\text {th }}$ and $6^{\text {th }}$ grade children.

\section{METHOD}

\section{Participants}

Two government Kannada medium schools, one from urban and one from village areas, participated on the study. A total of 110 students from $4^{\text {th }}, 5^{\text {th }}$ and $6^{\text {th }}$ grades took part in the study. Out of these 110 students, there were 31 students from $4^{\text {th }}$ grade, 41 from $5^{\text {th }}$ grade and 38 from $6^{\text {th }}$ grade selected randomly. All children are participated in the study have Kannada as their mother tongue. 


\section{Exclusion Criteria}

The study does not include children with sensory impairment, developmental disabilities, children with very inconsistent school attendance patterns, children with severe health problems, children who speak more than one language and children whose mother tongue is not Kannada.

\section{Materials and Procedures}

Phonological Awareness test developed by Ananda Siddiah (Siddiah \& Venkatesh, 2014) was used in this study. This measure includes six different component tasks mentioned below and the test retest reliability was established for each component from the original author.

Table 1, Test-retest reliability scores on phonological awareness tasks

\begin{tabular}{|l|c|}
\hline \multicolumn{1}{|c|}{ Measures } & Reliability scores \\
\hline Rhyme Generation (RG) & 0.805 \\
\hline Phoneme Deletion (PD) & 0.695 \\
\hline Phoneme Reversal (PR) & 0.786 \\
\hline Syllable Deletion (SD) & 0.719 \\
\hline Syllable Reversal (SR) & 0.728 \\
\hline Spoonerism (Spo) & 0.726 \\
\hline
\end{tabular}

- $\quad$ Rhyme Generation: Children were asked to listen to the said word carefully and they had to generate or produce a word, which ended with the same sound as said word.

- $\quad$ Phoneme deletion: Children were asked to listen to the presented word. Then asked to delete a particular sound from the presented word and then report the remaining part.

- $\quad$ Phoneme reversal: Children were asked to listen to presented word and asked to tell the word by reversing the initial and final vowel sounds.

- $\quad$ Syllable deletion: Children were asked to listen to the presented word and then asked to report the resulting word by deleting a particular syllable of presented word.

- $\quad$ Syllable reversal: Children were asked to listen to a presented word, then asked reverse the order of the syllable and report the resulting word.

- Spoonerism: In this task, Children were presented a pair of words then asked to interchange the initial sounds and present the resulting pair of words.

\section{Procedure}

Phonological awareness test was administered individually in a quiet room at school.

\section{Analysis}

Descriptive statistic and ANOVA was performed to investigate the significant mean difference across the grades on different component of phonological awareness. Later Tukey post-hoc test was performed to find out the significant mean difference of specific groups on different

(C) The International Journal of Indian Psychology, ISSN 2348-5396 (e)| ISSN: 2349-3429 (p) | 102 
component of phonological awareness.

\section{RESULTS}

The objective of the study is to explore the pattern of performance on different component skills of phonological awareness.

Table 1 presents the mean score of $4^{\text {th }}, 5^{\text {th }}$ and $6^{\text {th }}$ graders on different subtests. Each subtest of phonological awareness has ten questions. The percentage of performance of groups on components of phonological awareness varies between; Rhyme generation $76 \%$ to $80 \%$, Phoneme deletion $41 \%$ to $50 \%$, Phoneme reversal $14 \%$ to $27 \%$, Syllable deletion $79 \%$ to $84 \%$, Syllable reversal 59\% to $73 \%$ and Spoonerism 22\% to 32\%. It is observable from Table 1 and Figure 1 that the mean difference between $4^{\text {th }}$ and $5^{\text {th }}$ graders is more on Syllable reversal, and Phoneme reversal compared to other components.

Figure 1 shows the performance of $4^{\text {th }}, 5^{\text {th }}$ and $6^{\text {th }}$ graders on each component increases across the grades. Mean scores are increasing across the grades on all the components. It is also noticeable from Figure 1 that the highest performance is on Syllable deletion, followed by Rhyme generation, Syllable reversal, Phoneme deletion, Spoonerism and Phoneme reversal.

The one- way ANOVA was performed in order to find out significant mean difference between groups on different components of phonological awareness. The results are presented in Table 2. The results from one-way ANOVA determined that there is no statistically significant difference between groups on RG, PD, PR, SD and SPO. However there is a statistically significant difference between groups on Syllable reversal, $\mathrm{F}(2,107)=5.636, p<0.05$.

Further a Tukey post-hoc test performed to find out which means are significantly different from each other on SR, Table 3, revealed the mean scores on SR of $5^{\text {th }}$ grade $(7.24+/-1.85, p=0.013)$ and $6^{\text {th }}$ grade $(7.34+/-1.94, \mathrm{p}=0.008)$ groups are statistically significantly lower when compared to mean scores of $4^{\text {th }}$ grade $(6.00+/-1.59)$ group. There were no statistically differences between the $5^{\text {th }}$ and $6^{\text {th }}$ grade groups $(p=.969)$. 
Phonological Awareness among Kannada Speaking Children: Analysis of Performance on Different Components of Phonological Awareness

Table 2, Summary of descriptive statistics shows mean and standard deviation of $4^{\text {th }}$, $5^{\text {th }}$ and $6^{\text {th }}$ graders.

\begin{tabular}{|l|l|l|l|l|l|l|}
\hline \multirow{2}{*}{$\begin{array}{l}\text { Phonological } \\
\text { awareness tasks }\end{array}$} & \multicolumn{3}{|c|}{$\begin{array}{c}4^{\text {th }} \text { Grade } \\
\text { (N = 31) }\end{array}$} & \multicolumn{2}{|c|}{$\begin{array}{c}5^{\text {th }} \text { Grade } \\
\text { (N = 41) }\end{array}$} & \multicolumn{2}{c|}{$\begin{array}{c}6^{\text {th }} \text { grade } \\
\text { (N = 38) }\end{array}$} \\
\cline { 2 - 8 } & $\mathbf{M}$ & SD & M & SD & M & SD \\
\hline Rhyme generation & 7.68 & 1.45 & 7.88 & 1.67 & 8.03 & 1.44 \\
\hline Phoneme deletion & 4.13 & 2.14 & 4.59 & 2.54 & 5.00 & 2.51 \\
\hline Phoneme reversal & 1.48 & 1.98 & 2.66 & 2.97 & 2.68 & 3.04 \\
\hline Syllable deletion & 7.90 & 1.27 & 8.34 & 1.24 & 8.40 & 1.35 \\
\hline Syllable reversal & 6.00 & 1.59 & 7.24 & 1.85 & 7.34 & 1.94 \\
\hline Spoonerism & 2.29 & 2.88 & 3.22 & 3.55 & 3.24 & 3.19 \\
\hline
\end{tabular}

Figure 1 Mean score of different components of phonological awareness test of different grades.

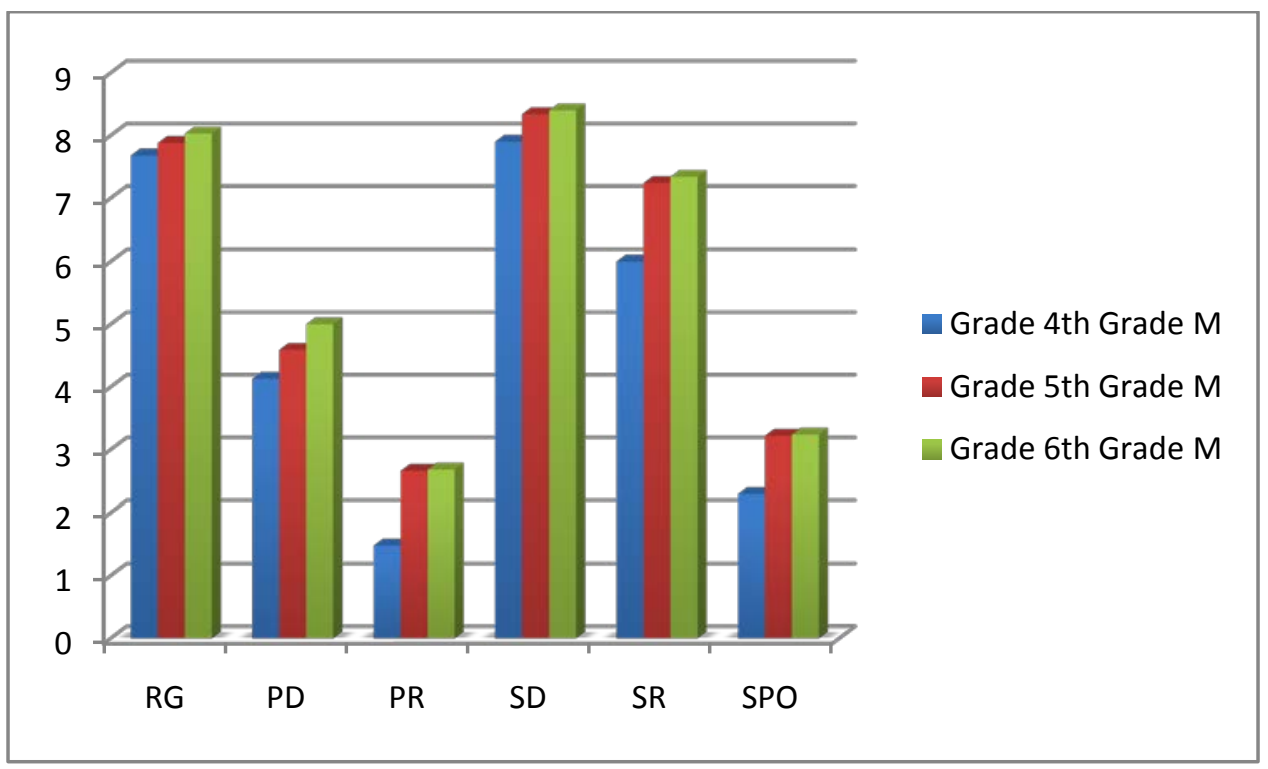

RG = Rhyme Generation, $\mathrm{PD}=$ Phoneme Deletion, $\mathrm{PR}=$ Phoneme Reversal, $\mathrm{SD}=$ Syllable Deletion, SR $=$ Syllable Reversal, $\mathrm{SPO}=$ Spoonerism 
Phonological Awareness among Kannada Speaking Children: Analysis of Performance on Different Components of Phonological Awareness

Table 3, Summary of ANOVA results of $4^{\text {th }}, 5^{\text {th }}$ and $6^{\text {th }}$ grade children on different component of phonological awareness test.

\begin{tabular}{|c|c|c|c|c|c|}
\hline Task & & $\begin{array}{r}\text { Sum of } \\
\text { Squares }\end{array}$ & df & $\mathbf{F}$ & Sig \\
\hline \multirow[t]{3}{*}{ RG } & Btween Groups & 2.080 & 2 & .441 & .644 \\
\hline & Within Groups & 252.138 & 107 & & \\
\hline & Total & 254.218 & 109 & & \\
\hline \multirow[t]{3}{*}{ PD } & Between Groups & 12.965 & 2 & 1.102 & .336 \\
\hline & Within Groups & 629.435 & 107 & & \\
\hline & Total & 642.400 & 109 & & \\
\hline \multirow[t]{3}{*}{ PR } & Between Groups & 31.383 & 2 & 2.065 & .132 \\
\hline & Within Groups & 813.172 & 107 & & \\
\hline & Total & 844.555 & 109 & & \\
\hline \multirow[t]{3}{*}{ SD } & Between Groups & 4.846 & 2 & 1.465 & .236 \\
\hline & Within Groups & 177.008 & 107 & & \\
\hline & Total & 181.855 & 109 & & \\
\hline \multirow[t]{3}{*}{ SR } & Between Groups & 37.305 & 2 & 5.636 & $.005^{*}$ \\
\hline & Within Groups & 354.114 & 107 & & \\
\hline & Total & 391.418 & 109 & & \\
\hline \multirow[t]{3}{*}{ SPO } & Between Groups & 19.575 & 2 & .928 & .398 \\
\hline & Within Groups & 1128.280 & 107 & & \\
\hline & Total & 1147.855 & 109 & & \\
\hline
\end{tabular}

${ }^{*} \mathrm{p}<0.05$

RG = Rhyme Generation, $\mathrm{PD}=$ Phoneme Deletion, $\mathrm{PR}=$ Phoneme Reversal, SD $=$ Syllable

Deletion, SR = Syllable Reversal, SPO = Spoonerism

Table 4, Summary of Tukey's multiple comparison lists

\begin{tabular}{|l|l|l|l|}
\hline PA measures & & \multicolumn{2}{|c|}{ Grades } \\
\hline & Grades & $\mathbf{4}$ & $\mathbf{5}$ \\
\hline SR & 4 & & \\
\hline & 5 & $.013^{*}$ & \\
\hline & 6 & $.008^{*}$ & .969 \\
\hline
\end{tabular}

*p $=0.05$

RG = Rhyme Generation, PD = Phoneme Deletion, $\mathrm{PR}=$ Phoneme Reversal, $\mathrm{SD}=$ Syllable Deletion, SR = Syllable Reversal, SPO = Spoonerism 


\section{Phonological Awareness among Kannada Speaking Children: Analysis of Performance on Different}

Components of Phonological Awareness

\section{DISCUSSION}

The present study explores the performance on different components of phonological awareness among $4^{\text {th }}, 5^{\text {th }}$ and $6^{\text {th }}$ grade Kannada medium school going children. The results show that the performance is not similar on all the components of phonological awareness tasks, the performance on each task differs with in the grade and across the grade. This may suggest that, not all phonological awareness tasks are equal (Ziegler \& Goswami, 2005) and cognitive processing demand differs when processing different phonological awareness task.

There is a slight increase in performance across the grades on all phonological awareness tasks. It might be influenced by cognitive development, the increased language exposure by grades and instruction. On the basis of level of performance it can be extracted from the results that processing of syllable level tasks (Nag \& Snowling (n.d.1) and rime level tasks is easier compared to phoneme level tasks across the grades.

The performance sequence, indiscriminate of their grades, on component tasks of phonological awareness showed syllable deletion (highest performance) - Rhyme generation - Syllable reversal - Phoneme deletion - Spoonerism - Phoneme reversal (lowest). This present outcome is in accordance with the sequence, mastery of word level skills first - syllable level - rime level - phoneme level as mentioned by Ziegler and Goswami (2005).

The results revealed that the performance on syllable processing tasks are better than phoneme processing tasks, this finding is consistent with findings of the study done on young Kannada learning children (Nag \& Snowling (n.d.2)). Further the phoneme processing skills are not well developed in young children, $4^{\text {th }}, 5^{\text {th }}$ and $6^{\text {th }}$ grade, which are learning Kannada orthography, however consistent findings in alphabetic orthographies revealed that phoneme processing skills are well developed in young children (de Jong \& van der Leij, 2003)

Nag (2007) and Nag \& Snowling (2011) consistently reported that linguistic features largely support early emergence of syllabic awareness and phoneme awareness develops gradually.

Among the limitations of the study it is worth to mentioning that the test items of the phonological awareness tasks include only non-words with simple letter combination (C, CV and CVV) combinations. We don't know the performance on the non-words with complex letter combinations (CCV). It only explores the phonological awareness without including any other reading measures.

\section{CONCLUSION}

The present study explores the phonological awareness among typically developing children. Findings revealed that syllable manipulation was the best, followed by rhyme generation and

(c) The International Journal of Indian Psychology, ISSN 2348-5396 (e)| ISSN: 2349-3429 (p) | 106 
phoneme manipulation, because of the supportive linguistic feature and linguistic environment were spoken language supports the early emergence of syllable awareness. Differential achievement on different phonological awareness tasks is because of the cognitive demand needed to process each task and the age of the children. Further, there is a slight increase in performance on each phonological awareness task across grades and the achievement on phonological awareness tasks across grades follows same sequence.

Linguistic environment were children oral language supports saliency of spoken syllables might play a major role in the emergence of syllable awareness, along with script specific features and language instruction influence on the phonological awareness skills.

\section{Acknowledgments}

The author appreciates all those who participated in the study and helped to facilitate the research process.

\section{Conflict of Interests}

The author declared no conflict of interests.

\section{REFERENCES}

Bentin, S., \& Leshem, H. (1993). On the interaction between phonological awareness and reading acquisition: It's a two way street. Annals of Dyslexia, 43, 125-148.

Bertelson, P., Morais, J., Alegria, J., \& Content, A. (1985).Phonetic analysis capacity and learning to read. Nature, 313, 73-74.

Bradley, L. \& Bryant, P. (1983). Categorizing sounds and learning to read: A causal connection, Nature 301: 419-421.

Bradley, L., \& Bryant, P. E. (1985).Rhyme and reason in reading and spelling. Ann Arbor: University of Michigan Press.

Bright, W. (1996).Kannada and Telugu writing. In P. Daniels \& W. Bright (Eds.), The world's writing systems. (pp. 413-419). New York: Oxford University Press.

Calfee, R.C., Lindamood, P. \& Lindamood, C. (1973). Acoustic-phonetic skill and reading kindergarten through twelfth grade, Journal of Educational Psychology 64: 293-298.

Cho, J-R., McBride-Chang, C. (2005).Correlates of Korean Hangul acquisition among kindergartners and second graders. Scientific Studies of Reading, 9, 3-16.

Cossu, G., Shankweiler, D., Liberman, I. Y., Katz, L., \& Tola, G. (1988).Awareness of phonological segments and reading ability in Italian children. Applied Psycolinguistics, 9, 1-16.

de Jong, P. F., \& van der Leij, A. (2003). Developmental changes in manifestation of a phonological deficit in dyslexic children learning to read a regular orthography. Journal of Educational Psychology, 95, 22-40.

deManrique, A. M. B., \& Gramigna, S. (1984). La segmentaciónfonológica y silábicaenninos de preescolar y primer grado. Lectura y Vida, 5/1, 4-14.

(C) The International Journal of Indian Psychology, ISSN 2348-5396 (e)| ISSN: 2349-3429 (p) | 107 
Gillon, G. T. (2000). The efficacy of phonological awareness intervention for children with spoken language impairments. Language, Speech and Hearing Services in Schools, 31, 126-141.

Johannes C. Ziegler \& Usha Goswami (2005). Reading Acquisition, Developmental Dyslexia, and Skilled Reading Across Languages: A Psycholinguistic Grain Size Theory, Psychological Bulletin, Vol131, No. 1, 3-29.

Juel, C., Griffith, P.L. \& Gough, P.B. (1986). Acquisition of literacy: A longitudinal study of children in first and second grade, Journal of Educational Psychology 78: 243-255.

Muter, V., Hulme, C., Snowling, M., \& Taylor, S. (1997). Segmentation, not rhyming, predicts early progress in learning to read. Journal of Experimental Child Psychology, 65, 370-396.

Nag, S. (2007). Early reading in Kannada: the pace of acquisition of orthographic knowledge and phonemic awareness. Journal of Research in Reading, 30, 7-22.

Nag, S., \& Snowling, M. J. (n.d.1). Children's reading development: Learning about sounds, symbols and cross-modal mappings. Retrieved April 5, 2016, from

https://www.york.ac.uk/media/psychology/crl/documents/sonalipapers/Children's reading development (for circulation).pdf

Nag, S., \&Snowling, M. J. (2011). Cognitive profiles of poor readers of Kannada. Reading and Writing, 24(6), 657-676.

Nag, S., \&Snowling, M. J. (n.d.2). Reading in an Alphasyllabary: Implications for a LanguageUniversal Theory of Learning to Read. Retrieved April 5, 2016, from https://www.york.ac.uk/media/psychology/crl/documents/sonalipapers/Reading in an alphasyllabary (pre-print version).pdf

Seymour, P.H.K., Aro, M., \& Erskine, J.M. (2003).Foundation literacy acquisition in European orthographies.British Journal of Psychology, 94, 143-174.

Siddaiah, A., \&Venkatesh K. S (2014). Phonological awareness and reading in children with and without dyslexia in English and Kannada. Journal of Psychosocial Research, 9, 361-370.

Simpson, G. B., \& Kang, H. (2004).Syllable processing in alphabetic Korean.Reading and Writing: An Interdisciplinary Journal, 17, 137-151.

Stanovich, K.E., Cunningham, A.E. \& Cramer, B.B. (1984). Assessing phonological awareness in kindergarten children: Issues of task comparability, Journal of Experimental Child Psychology 38: 175-190.

Swank, L. K., \& Catts, H. W. (1994).Phonological awareness and written word decoding. American Speech-Language- Hearing Association, 25, 9-14.

Tunmer, W. \&Nesdale, A. (1985). Phonemic segmentation skill and beginning reading, Journal of Educational Psychology 77: 417-427.

Tunmer, W. E., \& Nesdale, A. R. (1986). Phonemic segmentations kill and beginning reading. Journal of Educational Psychology, 77, 417-427.

Vaid, J., \& Gupta, A. (2002).Exploring word recognition in a semi-alphabetic script: The case of Devanagari. Brain and Language, 81, 679-690.

Vasanta, D. (2004). Processing phonological information in a semi-syllabic script: Developmental data from Telugu. Reading and Writing, 17, 59-78.

(C) The International Journal of Indian Psychology, ISSN 2348-5396 (e)| ISSN: 2349-3429 (p) | 108 


\section{Phonological Awareness among Kannada Speaking Children: Analysis of Performance on Different Components of Phonological Awareness}

Vellutino, F. R., Fletcher, J. M., Snowling, M. J., \& Scanlon, D. M. (2004). Specific reading disability (dyslexia): What have we learned in the past four decades? Journal of Child Psychology \& Psychiatry, 45, 2-40.

Wagner, R. K., Torgesen, J. K., Rashotte, C. A., Hecht, S. A., Barker, T. A., et al. (1997). Changing relationships between phonological processing abilities and word- level reading as children develop from beginning to skilled readers: A 5-year longitudinal study. Developmental Psychology, 33(3), 468-479.

Winskel, H., \& Iemwanthong, K. (2009).Reading and spelling acquisition in Thai children. Reading and Writing, 23, 1021-1053.

Ziegler, J., \& Goswami, U. (2005).Reading acquisition, developmental dyslexia, and skilled reading across languages: A psycholinguistic grain size theory. Psychological Bulletin, 131 (1), 3-29.

How to cite this article: K Nagaraja, Sampathkumar (2016), Phonological Awareness among Kannada Speaking Children: Analysis of Performance on Different Components of Phonological Awareness, International Journal of Indian Psychology, Volume 3, Issue 4, No. 68, ISSN:23485396 (e), ISSN:2349-3429 (p), DIP:18.01.201/20160304, ISBN:978-1-365-39398-3

(c) The International Journal of Indian Psychology, ISSN 2348-5396 (e)| ISSN: 2349-3429 (p) | 109 